\title{
NON-DESTRUCTIVE DOCUMENTATION METHODS FOR FUTURE SEISMIC AND DAMAGE ANALYSIS OF MODERN HERITAGE BUILDINGS USING CONTEMPORARY TOOLS
}

\author{
S. RAJABZADEH ${ }^{1 *}$, M. ESPONDA ${ }^{2}$, L. CORDERO ESPINOSA ${ }^{3}$ \\ ${ }^{1 *}$ Carleton Immersive Media Studio (CIMS), Bachelor of Architecture - Carleton University, Ottawa, \\ ON, Canada \\ sepidehrajabzadeh@cmail.carleton.ca \\ ${ }^{2}$ Associate Professor at the Azrieli School of Architecture - Carleton University, Ottawa, ON, Canada \\ - 1125 Colonel By Dr, Ottawa, ON K1S 5B6 \\ mariana esponda@carleton.ca \\ ${ }^{3}$ Bachelor of Architecture - National Autonomous University of Mexico (UNAM) \\ lailacorderoespinosa@gmail.com
}

Keywords: Felix Candela, Pabellón de Rayos Cósmicos, Hyperbolic Paraboloid, National Autonomous University of Mexico (UNAM), Photogrammetry, Digital Documentation, HBIM.

\begin{abstract}
This paper presents a comparative approach between a digital documentation workflow of a hyperbolic paraboloid heritage building using contemporary tools versus a traditional documentation technique. This documentation was undertaken to better understand the building's structure, its evolution, and to assess the performance of this modern concrete structure for future seismic and damage analysis. Furthermore, this paper discusses the challenges related to producing a Heritage Building Information Model (HBIM) of this building using point cloud data in Autodesk's Revit BIM-authoring software. This project states the importance of a parallel study between the traditional and the contemporary documentation methods; which led to discoveries about the current state of the extrados in the hyperbolic parabola after several earthquakes. Upon analyzing the HBIM and comparing it to the historical drawings, we discovered a gap between the moisture barrier membrane and the concrete shell. Visualizing the building in $3 D$ provides a deeper and more accurate understanding of the current state of this pavilion and is one of many advantages of using digital technologies. The insights provided by digital documentation techniques and analyzing the historical images of the pavilion showed that the curvature of the pavilion had changed over time. The results that we found imply two hypotheses. First, the profile of the curvature had been modified due to earthquakes, and second that the modification was due to improper maintenance of the pavilion, namely, multiple additions of the membrane layers. This could not have been detected by solely relying on traditional documentation techniques.
\end{abstract}

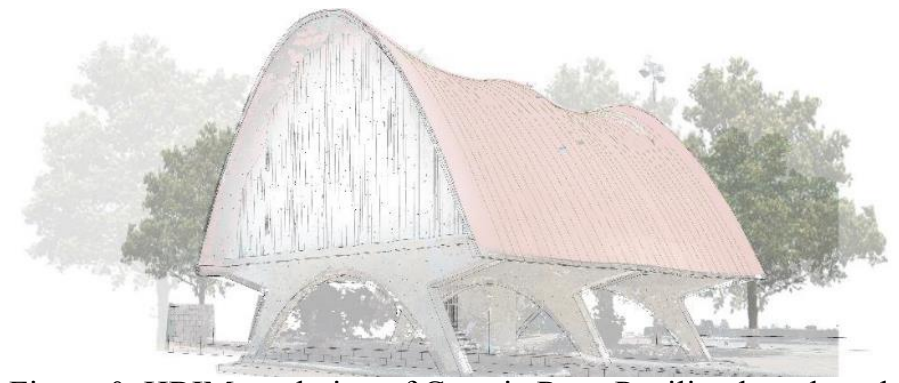

Figure 0. HBIM rendering of Cosmic Rays Pavilion based on the point cloud data 


\section{INTRODUCTION}

Felix Candela was born in Spain and emigrated to Mexico in 1939. He experimented with the hyperbolic paraboloid form for most of his career. His first project using this innovative construction was the Cosmic Rays Pavilion completed in 1951 in Mexico City, located on the campus of the National Autonomous University of Mexico (UNAM) [1], with a 5/8" (16 mm) thin reinforced concrete shell at their crown, increasing to $1 \frac{1 / 2 "}{2}(37 \mathrm{~mm})$ at the base [2]. The structure still stands after 70 years; despite undergoing 3 major earthquakes in 1985, 1999, and 2017 with magnitudes over 7.1. The pavilion was the thinnest highly durable shell membrane [3]. The strength of the pavilion is derived from its hyperbolic paraboloid geometry and craftsmanship [4]. It was important for the structure to be as thin as possible since its original purpose as a physics laboratory required cosmic rays to pass through the roof and to a device inside for measuring neutrons [3]. The pavilion now serves as a storage space for board games and sports equipment.

The preliminary objectives for the project were to produce two sets of drawings from the existing pavilion using two methods: traditional and digital. The two sets of drawings were then overlaid and compared with the original construction drawings of the pavilion done by Candela. The comparis on between the digital models and the original construction drawings revealed the

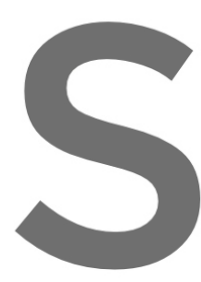
extent of decay a building can go through wit
consistent conservation and maintenance effor
The traditional documentation was done b
Fall of 2018 . Laila, a recent graduate from
measuring devices to document and produce the building. The digital approach was done
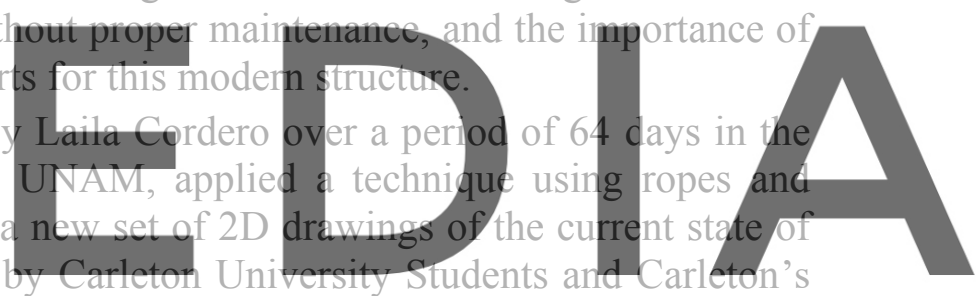

Immersive Media Studio (CIMS) from Canada over 49 days in May and June 2019. A team of

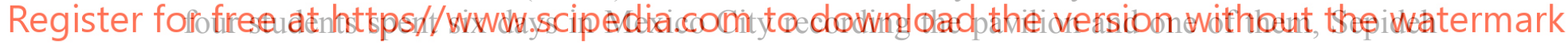

Rajabzadeh, continued working on the project until completion in Canada. This team used digital equipment such as DSLR cameras, a drone, and computer software to capture the existing geometry on site. The other 43 days were spent at CIMS in Canada processing the photogrammetry and 3D point cloud data, producing HBIM and 2D drawings.

This report aims to highlight the lack of research for the conservation of $20^{\text {th }}$ century concrete shells in Mexico, thus generating a field of interest to encourage more professionals from diverse fields to address the issue of proper interventions for modern architecture.

\subsection{Design}

Colin Faber describes the original intent of this pavilion in his book Candela: the shell builder as a barrel shape. Candela changed it into a hyperbolic paraboloid because he stated "the extreme thinness would require the extra stiffening offered by this form" [4]. (Figure 1)

"Candela was able to achieve a solution endowed with compelling three-dimensional force. On the ground level, three paraboloid-shaped arches rise up with protruding support. The upper portion of the arches serves as the structural framework of the laboratory, and the encompassing concrete membrane seems to rest in place above it without being anchored to the ground. The 
beauty of the design's three-dimensionality emerges directly from its clever devised proportion. As thin discs with well-balanced pressure and stress points, the arches do not seem to dominate the design: in light of the lateral bearing areas, the former seem to function like supports on the one hand and, because of their parabolic shape, convey a sense of elasticity on the other." [3]
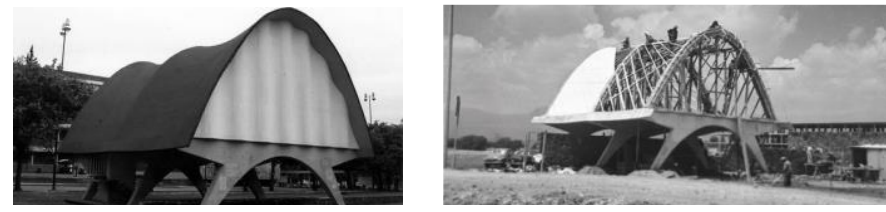

Figure 1. Left: Cosmic Rays Pavilion, Mexico City, 1951 [5]. Right: Cosmic Rays Pavilion in Construction, Mexico City [6]

\subsection{Construction}

Colin Faber reveals that a few days before the construction started, the officials at UNAM approached Candela to see his calculations for the shape of the pavilion, but he had none. Instead, he wrote a few pages explaining why the shape would support itself. It was easier done than said, because the hyperbolic paraboloids can be achieved by straight boards crossing at 60degree angles. After building Cosmic Rays, Candela went on to buitk and to explore more hyperbolic paraboloid structures. Later on in his career he realized that he lid not need to add the three stiffening arches to add to the strength of the pavilion, shape was strong enqugh without the arches [4].

\section{THE DOCUMENTA TION WORKFLOW}
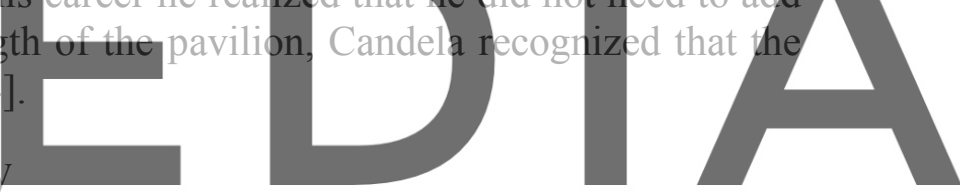

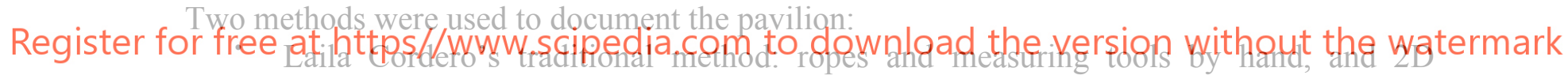
drawings [7]

- CINIS' digital method: DSLR cameras and a drone to capture, photogrammetry, an HBIM produced from point cloud data, and 2D drawings.

\section{1 Laila Cordero's workflow}

Laila, one of the authors, used an architectural surveying method that was a technique specifically applied to measure the geometry of the hyperbolic paraboloid shell. Laila created a complete analysis of the geometry of the pavilion shown in Figure 2.

To start the measurements, two essential elements were located: an axis and a reference level to identify the guide plane perpendicular to the parabola. Ropes were then installed across the interior connecting two legs of the parabolic columns at the bottom where they reached the floor. The rope was divided into $50 \mathrm{~cm}$ segments, and the height was measured by firing the distance meter twice which was positioned on a tripod. In the end, an average of the two measurements obtained at each point was calculated.

In this type of structure, it is possible to find an eccentricity between the center of the shell and the center of the floor. The eccentricity study was double checked by measuring the 


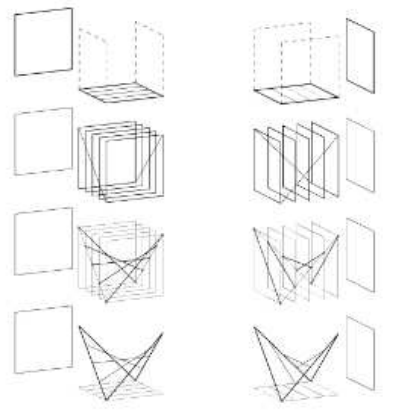

FIV RESII

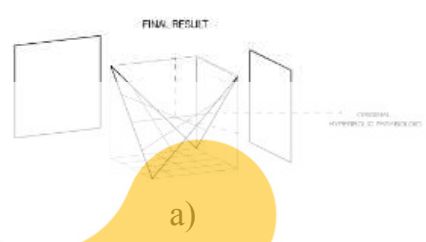

b) Exterior Measurements

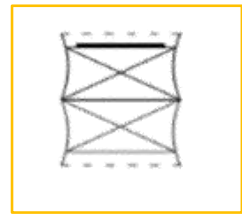

ELEVATION OF A BORDER PARABOLA

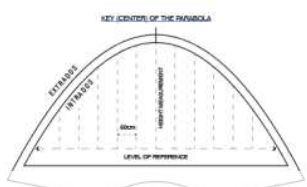

b) Interior Measurements

straight lines). b) Laila's drawings illustrating ropes that she used (the plan drawing in the yellow box) [7]

distance between the intersection of the diagonal ropes with respect to the ends of the supports and the center of the surface.

\section{Laila Cordero's thesis suggests the hypothesis that Fél} for Cosmic Rays Pavi elevations that were put they were drastically constructional drawings
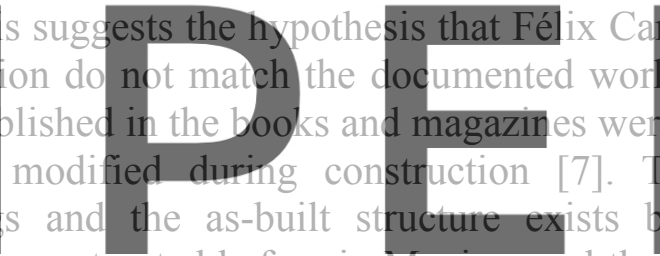

structures had not been constructed before in Mexico, and the
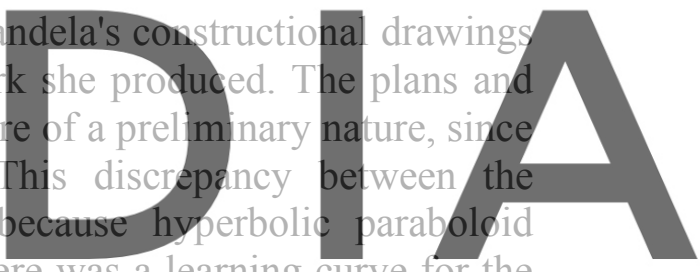
construction process which did not allow for a perfect recreation of the design. Also, throughout

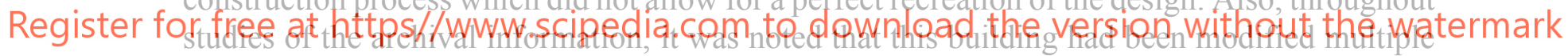
times during the construction because of its experimental nature. These are just a few of the reasons why this building needs to be preserved and properiy maintained [7].

\section{2 CIMS workflow while in Mexico (NPNT internship)}

Part of the research for this project was supported by The New Paradigm New Tools for Architectural Heritage in Canada (NPNT) research program supported by the Social Sciences and Humanities Research Council of Canada (SSHRC). The internship program focuses on using emerging digital technologies including the digitization of existing buildings using tools such as Photogrammetry with DSLR cameras and computer software. Some of the benefits of this documentation method explored through the NPNT program are efficiency of labour and ease of gathering data, while providing great accuracy.

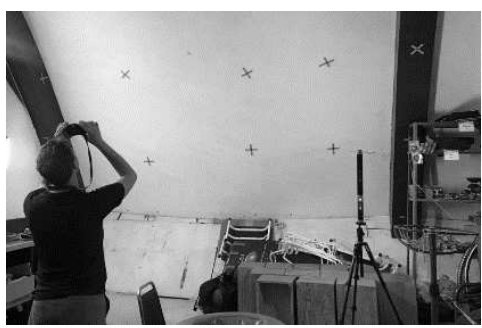

Figure 3. One of the Canadian students collecting interior photogrammetry data of the pavilion using a hand held DSLR camera. 
The project started with an introduction to the site and a tour of the University and Mexico City. Then, the documentation of the Cosmic Rays Pavilion began. Techniques used during this time included the use of an Unmanned Aerial Vehicle (UAV) to capture aerial photography of the roof and its curvature, as well as the site. Also, handheld cameras including the Nikon D5200, 24.1 MP (APS-C), and Nikon 40mm Macro Lens were used for terrestrial photogrammetry. Furthermore, an interior material catalogue using a gray chart was recorded.

Throughout the week, more interior and exterior photogrammetric images were taken as well as context elevation photos. Then, the exterior material catalogue was documented as well as an exterior condition assessment. The quality of photogrammetric models and data were tested while on site as well as the quality of elevation photos using Bentley ContextCapture and Adobe Photoshop. This was important to ensure all documentation was collected prior to leaving the site.
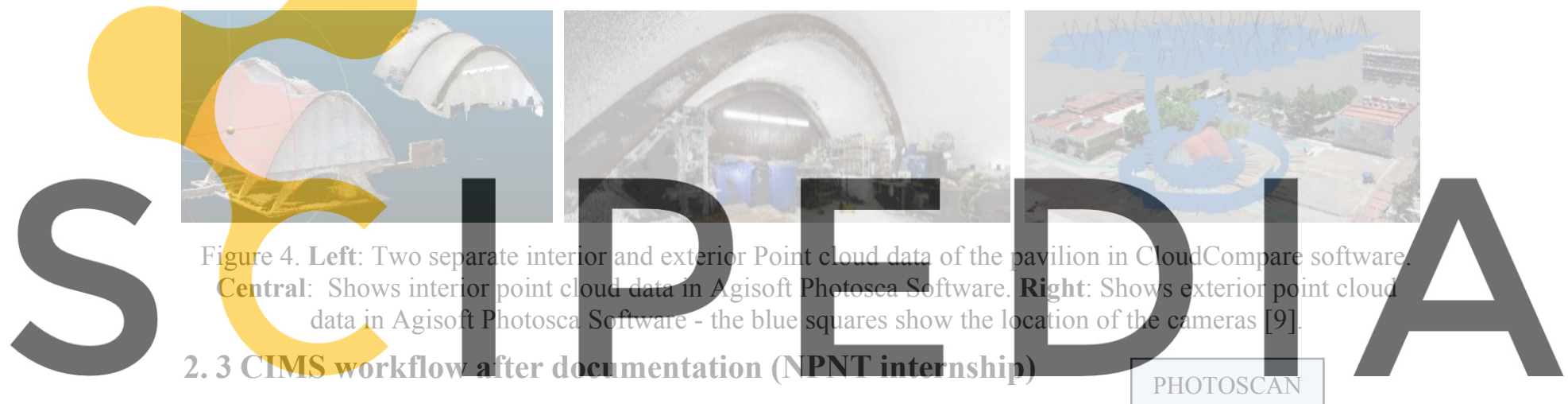

While students were getting to know the "contemporary tools"

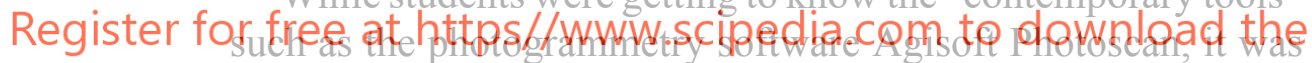

decided to create the interior and exterior point cloud models separately and merge them together to create one unified point cloud model. (Figure 4)

\subsubsection{Workflow in Agisoft Photoscan Software}

The diagram in Figure 5 shows the complete digital workflow that was performed to produce a point cloud model from photogrammetric data. The team created target points on the interior wall of the pavilion. These targets were located in the software to stitch the images together. After importing all of the images into the Agisoft Photoscan software, target points, which had been attached to the roof during data acquisition, were used to align the images together. The previously measured distance between the targets was used to accurately scale the model in Agisoft Photoscan (Figure 6) [9].

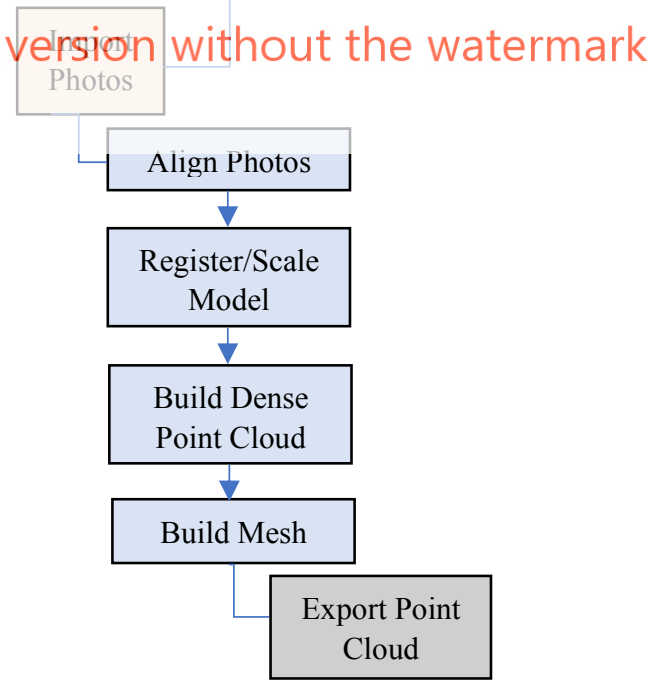

Figure 5. Photogrammetry workflow in Agisoft Photoscan [9]. 

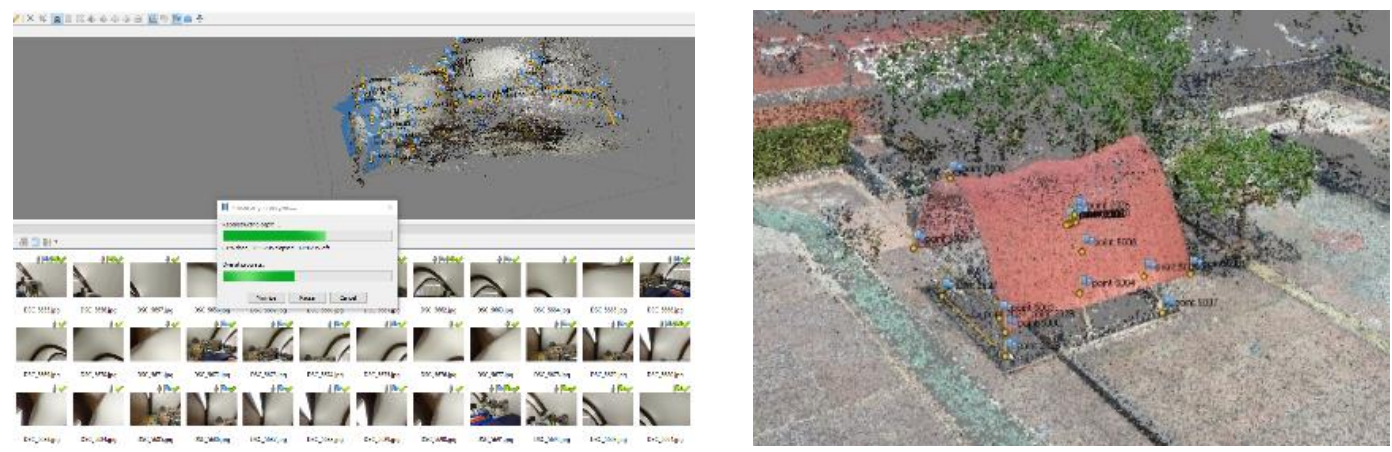

Figure 6. Left: Photo aligning process in Aigsoft Photoscan Software using the target points. Right: Dense cloud of the whole site created in Agisoft Photoscan Software [9].

Furthermore, a dense cloud was built to create the 3D point cloud model. Then, it was exported out of this software and imported into Revit to create an HBIM of the pavilion.

Once the point cloud data was imported to Revit, different strategies and protocols were applied to find the best methodology in order to create the double curved roof accurately. These different methods and their challenges are briefly mentioned in the challenge section of this

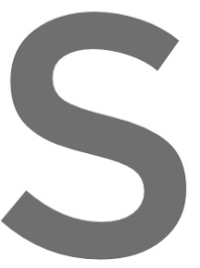
paper. The method that proved to be most accurate is explained in the following section: 2.3.2 Workflow in Revit Software

Both interior and exterior point eloud data to identify different glements of the building in
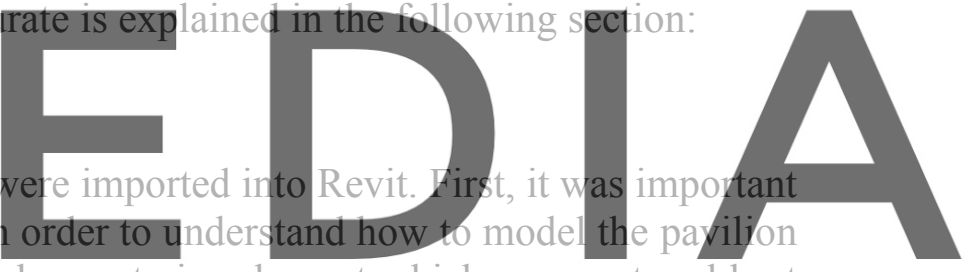

efficiently. The roof membrane was considered an exterior element which was captured best

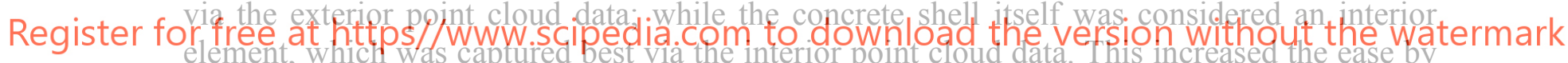

which the membrane and the concrete shell could be modelled, since the different point clouds can be turned on and off in Revit using visibility and view settings. The strategy to capture the shape of the hyperbolic paraboloid is described in Figure 7. Through the roof, thin sections were taken by introducing vertical reference planes in close proximity to one another. Using the section box tool, the curvature of each section on the roof was carefully traced with model lines. Then, while selecting all the model lines, the "Create Form" tool was used to create a surface that followed the curvature, deformations, and deviations of the documented roof membrane.
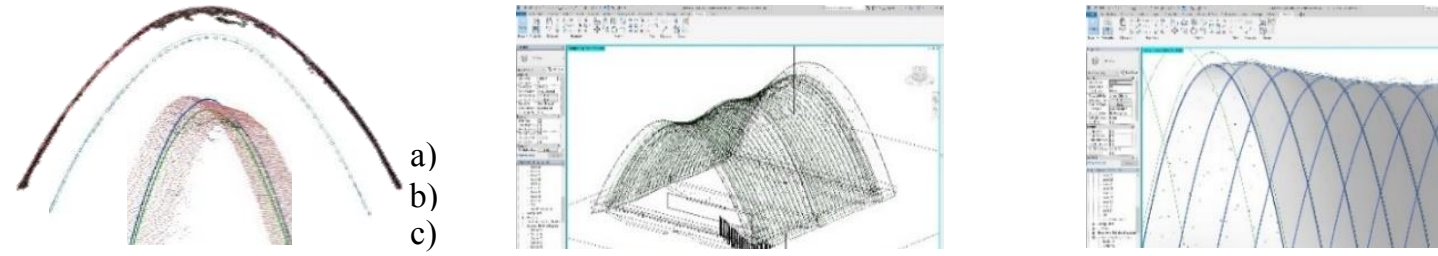

Figure 7. Left: a) Thin section of the point cloud model of the roof membrane [10], b) Model lines outlining the roof membrane and the concrete shell [11, 12], c) Thin section of the roof membrane with model lines [10].

Central: Roof membrane and the concrete shell model lines. Right: Green: The roof membrane model lines. Blue: The concrete shell model lines. 
This process was repeated to model the concrete shell, using interior point cloud data. Lastly, both surfaces were given proper thicknesses based on their point cloud data (Figure 8). The HBIM includes structural and mass elements together, and is developed accurately based on the existing conditions and geometry of the pavilion because of the original objectives of the project. However, this model could further be studied for seismic load analysis by converting it into a model for structural analysis.
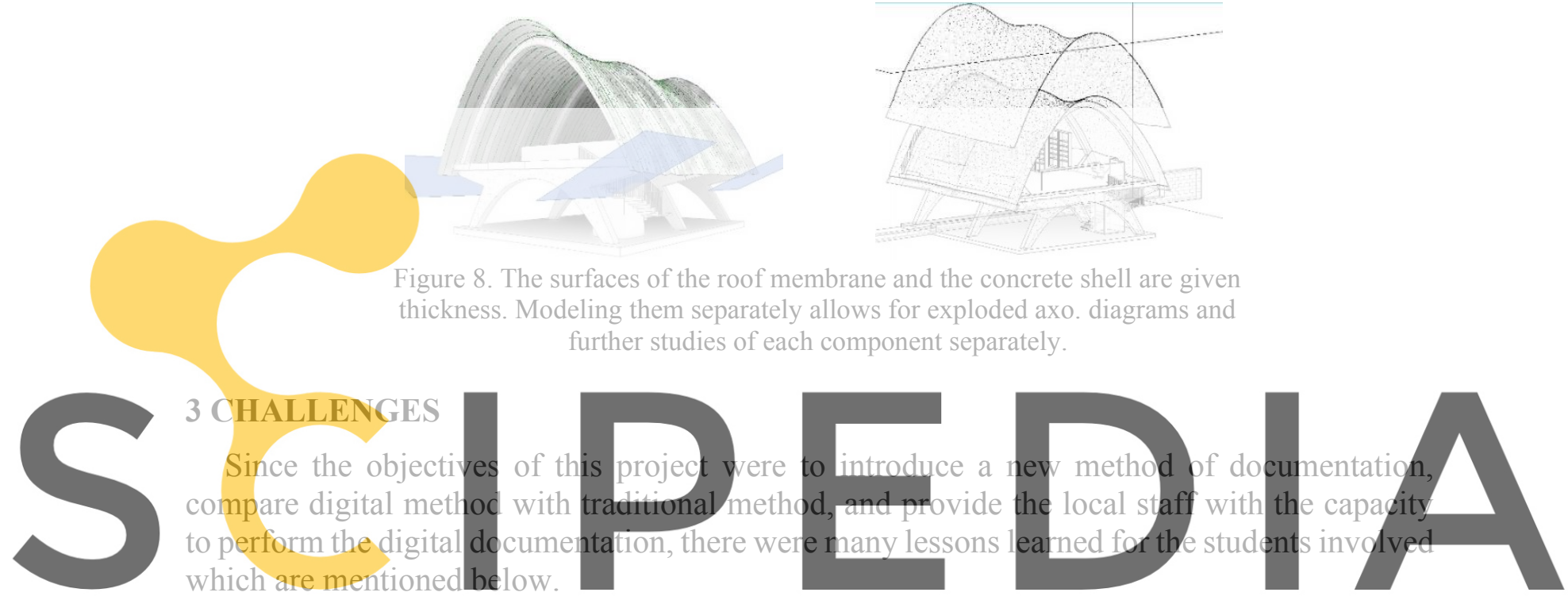

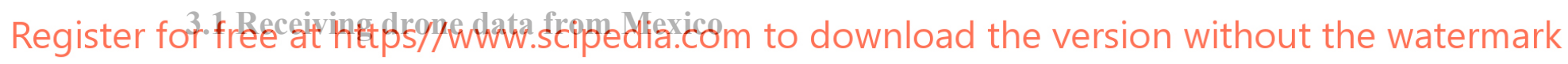

Although the drone was used while the team was still in Mexico, the drone data was only received in Canada while two weeks of the project was remaining. It was delayed due to security reasons prior to leaving Mexico. The Canadian team recorded the exterior data from ground level by handheld cameras and the point cloud model was missing data from the top of the roof. Once the drone info was received, the exterior photogrammetry was reprocessed to include the data from the top of the roof, aligned with the interior point cloud data, and then imported into Revit to be modelled (Figure 9).
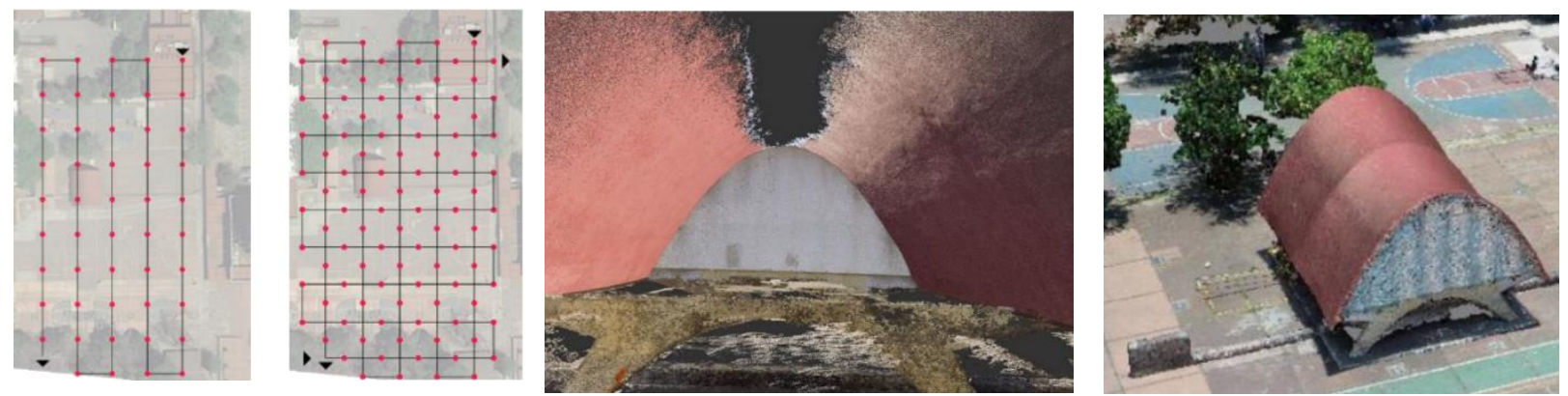

Figure 9. Left: Drone movement (Left: First round, red dots are the shots taken and Right: Second round).

Central: Exterior point cloud model before receiving drone information, the top part is missing. Right: Exterior point cloud model after receiving drone data. 


\subsection{Merging interior and exterior point cloud data manually}

One of the main lessons learned in this project arose from the fact that the main strategy was to rely on point-to-point correspondences for the software to merge the interior and the exterior point clouds. Later on, it was understood that there was a lack of redundancy in the process. Although there were thorough hand measurements taken by the team, no ground control points were collected in case of the software failure to stitch the pictures together.

The one common area between the interior and exterior is the railing on the stairs. Although there are many images of this part, the software could not reconcile the two point cloud data fully buy itself. We surmised that this did not work because the exposure levels in the images of the railings from inside of the pavilion were very different from those of outside. Therefore, the software could not recognize matching features between the sets of photographs and failed to merge them (Figure 10).

Consequently, the two point clouds had to be merged manually, by matching all the measurements as closely as possible in order to reduce the errors.

Having encountered such challenges played an essential role in helping the team understand the limits of the software. Moving forward, it is recommended to have at least three common targets that are captured by both the interior and exterior photographs.

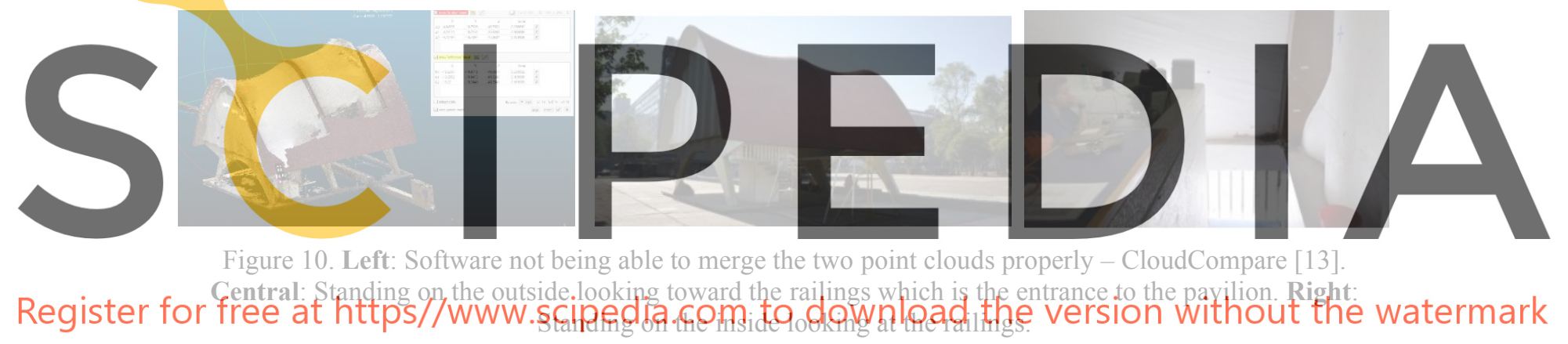

\subsection{Location of the Building}

Beyond the technical challenges of this work, there were other difficulties in the recording process. One of which was the location of the building: Cosmic Rays Pavilion is located on the busiest part of the campus of UNAM. The campus could not restrict access for the documentation work, so there were frequently many students near the pavilion. The team had to take a lot of images at different times of the day and different days of the week, with different weather and lighting conditions in order to record high quality images for the production of high quality point cloud data without people and other obstructions in the photos.

\section{NEW DISCOVERIES}

Once the HBIM was developed, more in-depth studies were done to understand how the building was constructed and evolved throughout time. One of the more interesting discoveries was that there is a gap between the red roof membrane and the hyperbolic paraboloid concrete shell. Further studies on the model revealed that this gap varies throughout the entirety of the pavilion and it is at its greatest in the middle of the roof (Figure 11). 
Once this new piece of information was shared with Laila, she provided us with thermal images which strengthened our finding about the poor maintenance and vulnerable state of the concrete roof (Figure 12).

In Figure 12 the picture on the left shows an even distribution of heat on the roof membrane taken from outside, but the picture on the right shows uneven heat distribution on the concrete shell itself taken from the inside. The extent of the membrane failure was apparent in the concrete shell through the thermal images. The image reinforces the discovery of the gap between the roof membrane and the concrete shell, and the nonuniformity of the gap. This new piece of information shows the roof membrane has not been maintained properly over the years. It was speculated that the poor maintenance of the membrane may have led to cracks and openings in the membrane, which allowed water and moisture into the concrete shell resulting in its gradual deterioration.

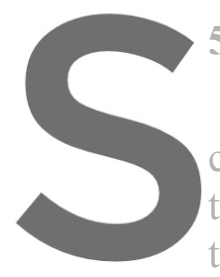

\section{DELIVERABLES \\ At the start of the pitoj \\ compare the differen \\ traditional and digital,}

there were differences $b$

the building and the original drawings.

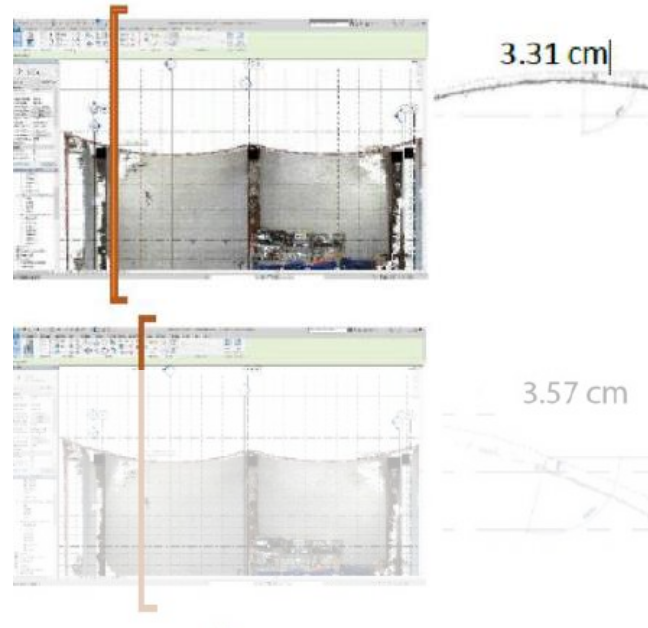

Register for documentation method were overlaid, they aligned very well with negligible differences (Figure 13). However, once the new drawings were overlaid with the original construction drawings, they did not correlate (Figure 13).

Since Cosmic Rays Pavilion was Felix Candela's first hyperbolic paraboloid, he learned how to solve constructional challenges with this geometry along the way during construction. The lack of accurate construction, or as-built drawings of this pavilion means that if the building is not properly taken care of and gets damaged over time, it cannot be rebuilt as it looks now. The original construction drawings were only done as a guideline for how to approach the construction process of the hyperbolic paraboloid using reinforced concrete, however the execution and final product showed a different result.

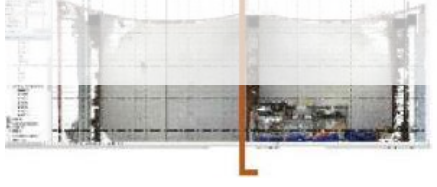

Figure 11. Series of sections showing the gap size between the roof membrane and the concrete shell - East Section

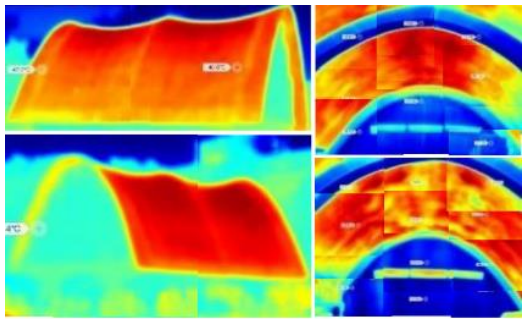

Figure 12. Thermal images [7] 

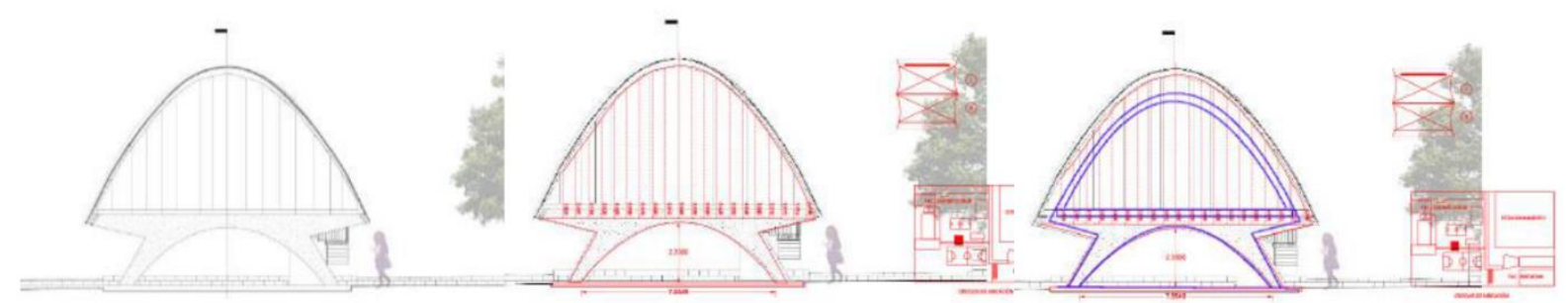

Figure 13. Left: 2D drawing done by CIMS using Revit software and point cloud data. Central: 2D drawing done by CIMS using Revit software and point cloud data (In red: Laila Cordero's drawing) [7]. Right: 2D drawing done by CIMS using Revit software and point cloud data (In red: Laila Cordero's drawing, in blue:

Original construction drawing) $[7,14]$

\section{CONCLUSION}

After the HBIM creation of the pavilion, collaboration with Laila Cordero's traditional measurements, and a thorough study of the archival documents; the results show that the traditional and contemporary techniques produced the same results. However, using new digital techniques led to more in-depth discoveries of the state of the building. Also, our hypothesis, which speculated that there is a gap between the concrete shell and the roof membrane, which was a result of poor maintenance, was proven to be true. One of the stakeholders, Julio Valencia Navar General de Obras y Conservación) from UNAM, has since confirmed that there is the roof membrane and the concrete shell. Over the years, there concrete shell due to the improper removal of the waterproofing damage is changing the curvature, and probably

Although the project was missing control points, the relatively small scale of the project allowed

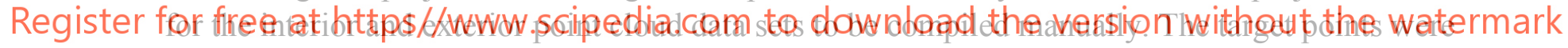
accurate to allow for a comprehensive point cloud data sets of the pavilion to be created using photogrammetry. While laser scanners can quickly produce a point cloud, they are less accessible and more expensive than DSLR cameras and drones. Using photogrammetry technique helped facilitate a maintenance approach to visually show which part of the building required immediate attention.

The collaborative and comparative approach developed for recording the as-found conditions of the Cosmic Rays Pavilion provided an opportunity for the local staff to have a meaningful learning experience about the value of this building and proper conservation techniques. Moreover, the HBIM can be studied further for seismic analysis on the concrete shell, damage scenarios, and risk management purposes in the future.

Finally, it was crucial to continually reference the archival images and to understand the traditional technique that was used in order to better understand the building, and to make sure the analyses provided by the contemporary tools were accurate. 


\section{ACKNOWLEDGEMENT}

This research was supported by the Social Sciences and Humanities Research Council of Canada (SSHRC). Special thanks go to Professor Stephen Fai (principal Investigator of the New Paradigm/New Tools internship program and Director at CIMS), Lara Chow (Associate Director at CIMS), Mariana Esponda for leading the project, Carleton Immersive Media Studio (CIMS), Carleton University. Thanks to Adrian Soble, Khadija Waheed and Luis Panchi for helping gather the data for the project. Laila Cordero Espinosa for sharing her undergraduate thesis. Special thanks to Dr. Xavier Cortes Rocha, Dr. Juan Ignacio del Cueto Ruiz-Funes, Mtro. Julio Valencia Navarro (Dirección General de Obras y Conservación), Arq. Alberto Hernández, EPY CIG Company: Ing. Alejandro Rodriguez Garcia, Ing. Miguel Eduardo Chavez Huerta, and Alejandro Minero Huerta for exchanging their knowledge. National Autonomous University of Mexico (UNAM) for allowing the team to work on the site for data collection.

\section{REFERENCES}

[1] Interview with Dr. Juan Ignacio del Cueto (May 2019).

[2] Moreyra Garlock, M.E. Billington, D.P. Félix Candela: Engineer, Builder, Structural Artist. New Haven, Conn: Yale University Press (2008, p. 91).

[3] De Anda Alanis, E. X. Candela. Mexio: Taschen (2008).

[4] Faber, C. Candela: The Shell Builder. New York: Reinhold Pub. Corp., (1963).

[5] Cosmic Ray Pavilion. Architectuul.com. Available at:

http://architectuul.com/architecture/cosmic-ray-pavilion

[6] Del Cueto Ruiz-Funes, J.I. CANDELA ACE. Acción Cultural Española (AC/E), TF Graphic Arts, (2011). Available at:

https://www.accioncultural.es/media/Default\%20Files/files/publicaciones/files/catalogo candela. pdf

[7] Cordero Espinosa, L. G. Undergraduate tesis. Pavellón de Rayos Cósmicos: pasado, presente y futuro. National Autonomous University of Mexico, Mexico. (2019).

[8] Aimond, F. F. Etude statique des voiles minces en paraboloide hiperbolique, travaillant sans flexion. memories de la ASCC. INT. DESPONTS ET CHARPENTES. VOL. IV.

[9] Carleton Immersive Media Studio (CIMS). Processing in Photoscan, pre-training workshop. Carleton University, Ottawa, Canada. (2018).

[10] Godin A.A. Algonquin BIM workshop tutorials. Carleton Immersive Media Studio (CIMS) Carleton University, Ottawa, Canada. (2018).

[11] BIM - Revit 3D Organic Form 03 Tensile Structure. Non-Stop Learning101 Youtube. (2017). Available at:

https://www.youtube.com/watch?v=9 jJBtKGLyc\&fbclid=IwAR1PrpN6Gw7iNQWyo5K1QyP1 ef 1NJasWfYVf7 qX5ed8uDcop-rY9AcSVE

[12] Learn revit in 5 Minutes- Mass forme Felix Candela. Niko G. Youtube. (2016). Available at: https://www.youtube.com/watch?v=mxwGfNWwM-

I\&fbclid=IwAR1Bjmc4i23eThRigbOeo7rCvh1jpNtyn2 tn -rbRe7XpEFTWDTEGq1tUk

[13] Aligning \& Merging .DP Data in CloudCompare. DotProduct Youtube. (2016). Available

at: https://www.youtube.com/watch?v=48xILOe9d7I\&fbclid=IwAR0PieUuwsVVbM1-1764xM2HvTufFd-XLQuAvqML0BEfMjEu_nj-zfbzgM

[14] Mendoza Morfín, G. Campus Central C.U. Lecturas de un Patrimonio Vivo. Facultad de Arquitectura UNAM. (2019). 
[15] Flelix Candela, Major Works. The Princeton University Art Museum, (2008). Available at: https://artmuseum.princeton.edu/legacy-projects/Candela/cosmicrays.html

[16] Morganti C., Bartolomei C. Digital Survey and Documentation of La Habana Vieja in Cuba. In: Ioannides M., Martins J., Žarnić R., Lim V. (eds) Advances in Digital Cultural Heritage. Lecture Notes in Computer Science, vol 10754. Springer, Cham. (2018). [17] Ace D., Marrs J., Santana Quintero M., Barazzetti L., Demas M., Friedman L., Roby T., Chamberlain M., Duong M., Awad R. Documenting Nea Paphos for Conservation and Management. Carleton Immersive Media Studio (CIMS) Carleton University Canada, Politecnico di Milano, Department of Architecture, Built Environment and Construction Engineering Italy, Getty Conservation Institute U.S., Department of Antiquities of Cyprus., (2019). 